\title{
EL PUERTO COMO ESPACIO DE DIÁLOGO EN EL TANGO Y EN EL FADO: UN ENFOQUE GEOCRÍTICO
}

\author{
The port as a space of dialogue in Tango and Fado: a Geocritical approach
}

\section{RESUMEN}

Durante los últimos años distintos artistas argentinos han reunido en sus repertorios el tango y el fado, dos géneros poético-musicales cuyo auge se produjo durante una parte del siglo XX. La cantante Karina Beorlegui es la figura sobresaliente de este movimiento, puesto que promovió actividades como el Fado Tango Club (2008-2018) y el Festival Porteño de Tango y Fado (2012, 2014, 2017, 2019).

Las canciones elegidas suelen pertenecer, por un lado, al tango canción y, por el otro, al fado tradicional y al fado canción. De ahí que los repertorios mixtos de tango y fado se propongan como una relectura de la tradición de ambos géneros a la luz del diálogo de uno con otro. Quienes se han planteado las posibles convergencias entre el tango y el fado destacan, fundamentalmente, ciertas afinidades poéticas y su condición de haberse gestado en ciudades portuarias (Beorlegui, Vera Sepúlveda, Gouveia). En este marco, el propósito de este artículo es sopesar la consideración de las letrísticas del tango y del fado como poéticas portuarias, y de la ciudad puerto como espacio heterotópico (Foucault, Westphal) fundante de su identidad. Partimos de la hipótesis de que el puerto se configuraría como una matriz de sentido en el entramado poético de estas canciones, susceptible de convertirse en una categoría de análisis que supera lo territorial, pues por su propia definición el puerto es puente y pasaje por el que avanza el influjo del mar, que modela el suelo urbano y, consecuentemente, la relación del sujeto con el espacio.

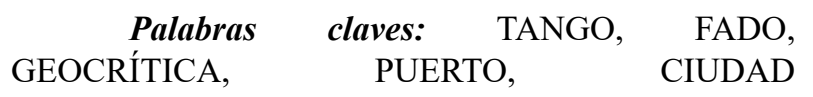

\section{UNIVERSUM

\author{
DULCE MARÍA
} \\ DALBOSCO}

Centro de Estudios de Literatura

Comparada "M. T. Maiorana", Facultad de Filosofía y Letras, Universidad Católica Argentina, CONICET, Argentina.

Correo electrónico:

dulcedalbosco@hotmail.com

ORCID: 0000-0001-5148-8892

ResearchGate:

Scholar.google:

Academia.edu:

Artículo recibido el 19 de noviembre, 2019. Aceptado el 28 de febrero, 2020.

Web: http://universum.utalca.cl | ISSN: 0716-498X - 0718-2376 


\begin{abstract}
In recent years, different Argentinian artists have gathered Tango and Fado in their repertoires, two musical and poetical genres which boom took place during some part of the Twentieth Century. Singer Karina Beorlegui is the outstanding figure of this movement, since she has promoted activities such as the Fado Tango Club (2008-2018) and the Festival Porteño of Tango and Fado (2012, 2014, 2017, 2019).

The chosen songs usually belong, on one hand, to the Tango-song period, and, on the other, to the Fados known as traditional Fado and Fado-song. Consequently, the mixed repertoires of Tango and Fado propose a rereading of the tradition of both genres and promote the dialogue between them. Those who have thought about the possible convergences between Tango and Fado have highlighted, fundamentally, certain poetic affinities and their condition of having been developed in port cities (Beorlegui, Vera Sepúlveda, Gouveia). In this context, the purpose of this article is to consider the lyrics of Tango and Fado as Port Poetics, and the port city as a heterotopia (Foucault, Westphal) in which its identity is based. Our starting point is the hypothesis that the port could be conceived as a matrix of meaning in the poetic structure of these songs. In fact, the port city could become a category of analysis that exceeds its territorial aspect, because by definition the port is a bridge and a passage through which the influence of the sea advances, models the urban land and, consequently, the relationship of the individual with space.
\end{abstract}

Keywords: TANGO, FADO, GEOCRITIC, PORT, CITY

Desde comienzos del nuevo milenio distintos artistas argentinos han reunido en sus repertorios el tango y el fado, dos géneros poético-musicales cuya vigencia durante el siglo XX se había mantenido, a grandes rasgos y con altibajos, entre los años veinte y los sesenta. ${ }^{1}$ Entre tales artistas podemos mencionar a Karina Beorlegui y los primos Gabino, a Mariana Accinelli, a

1 En el caso del tango, hubo dos períodos de auge compositivo. El primero fue la década de los veinte, durante la Guardia Nueva, mientras que el segundo fue la llamada época de oro, usualmente demarcada entre 1940 y 1955 (García Brunelli, 2010). Finalizada esta etapa, el tango es desplazado por otras músicas y pierde vitalidad. En cuanto al fado, cuyo surgimiento fue anterior al del tango, la situación fue un poco distinta. Eduardo Sucena sostiene que sus años áureos estuvieron comprendidos entre las décadas de los treinta y de los cincuenta (2008: 213). En este lapso surge la cantante más reconocida del género, Amália Rodrigues, quien no solo alcanzó un éxito extraordinario de proyección internacional, sino que además introdujo novedades estéticas en el fado. En efecto, en los años sesenta llevó a cabo una renovación formal junto con el compositor francés Alain Oulman, quienes musicalizaron versos de poetas lusitanos de todos los tiempos y le confirieron mayor vuelo intelectual al género. Luego de la caída del Estado Novo, a mediados de los años setenta, el fado entra en declive. Tras décadas de retracción, durante los noventa ambos géneros lograron captar la atención de un público nuevo, en una etapa que aunó evocación y experimentación (cfr. Castelo-Branco, 2000). 
Andrea Eletti y Grupotango, entre otros. También han aparecido agrupaciones musicales argentinas consagradas exclusivamente difundir la música lusitana, particularmente el fado, como Fadeiros, Alma Lusa o Luz de lágrima. La cantante Karina Beorlegui es la figura pionera y sobresaliente del movimiento que aúna tango y fado, puesto que ha promovido actividades como el Fado Tango Club (2008-2018) y el Festival Porteño de Tango y Fado (2012, 2014, 2017 y 2019). ${ }^{2}$

Las canciones elegidas por estos artistas suelen pertenecer, por un lado, al tango canción y, por el otro, al fado tradicional y al fado canción. ${ }^{3}$ Cabe destacar que no se trata de un ejercicio de fusión, dado que cada género es generalmente cantado en su propio idioma y musicalizado de acuerdo con sus códigos básicos. En consecuencia, los repertorios mixtos de tango y fado se proponen como una relectura de la tradición de ambos géneros a la luz del diálogo de uno con otro. También así se lleva a cabo una reinterpretación,

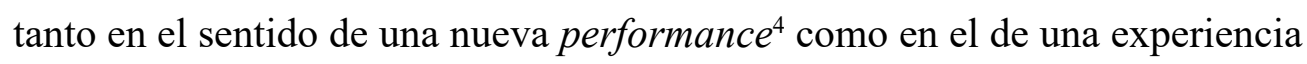
de escucha conjunta de alcance crítico, por cuanto permite pensar en las conexiones y los contrastes entre ambos géneros. Si bien el tango y el fado no son particularmente semejantes en el aspecto melódico, ciertas características

2 Estas actividades han fomentado la escucha conjunta del tango y el fado al hacer convivir ambos géneros en un mismo espectáculo musical. Las cuatro ediciones del Festival Porteño de Tango y Fado, declaradas de Interés Cultural por el Gobierno de la Ciudad de Buenos Aires, han convocado a compartir escenario a figuras nacionales y portuguesas. Los invitados lusitanos que han participado de estos encuentros son los fadistas Zé Perdigão, Paulo Valentim, Bruno Costa y Mafalda Arnauth.

3 En líneas generales podemos decir que entre el fado tradicional y el fado canción hay una diferencia de estructura, puesto que este último presenta un estribillo y una mayor complejidad armónica. El primero está presente desde la aparición del fado, mientras que el segundo surgió por influencia del teatro, entre fines del siglo XIX y principios del XX (Gouveia, 2013: 43-44).

4 Aquí la palabra performance hace referencia a la interpretación vocal y a la puesta en escena de las canciones por parte de los artistas. Así entendido, el concepto implica una superación de la repetición mimética, puesto que "incluye también la posibilidad de cambio, crítica y creatividad dentro de la repetición” (Taylor, 2012: 17). Performance es un término polisémico que, como sostiene Diana Taylor, "connota simultáneamente un proceso, una práctica, una episteme, un modo de transmisión, una realización y un medio de intervenir en el mundo" (2005: 5). A lo largo del artículo emplearemos performance y sus derivados - performático, performatizar, etcétera - en sus distintas acepciones que, en caso de ser necesario, serán oportunamente especificadas. 
musicales y performáticas permiten que los mismos artistas — cantantes y músicos - puedan ejecutar ambos géneros sin que suene necesariamente forzado. Sin lugar a duda, una compatibilidad remarcable es el hecho de que en ambas tradiciones la guitarra constituya un acompañamiento habitual del vocalista, ${ }^{5}$ sea este hombre o mujer. El caso de Karina Beorlegui y los Primos Gabino es ilustrativo. Beorlegui comenzó a incorporar fados clásicos en su repertorio tanguero, como lo demuestra su disco Caprichosa (2003), hasta que luego se unió al trío de guitarras Los primos Gabino, integrado por Esteban Ruiz Barrea, Juan Pablo Esmok Lew y Nacho Cabello, el último de los cuales empezó a tocar también la guitarra portuguesa. Esta agrupación grabó dos discos de tango y fado: Mañana zarpa un barco (2008) y Puertos cardinales (2012). Asimismo, otros aspectos que permiten una ejecución conjunta de las dos músicas son el papel destacado que los vocalistas han desempeñado en ambos géneros y sus letrísticas de carácter popular, vinculadas con la experiencia de la vida moderna en la ciudad.

Estas propuestas artísticas nos han llevado a preguntarnos hasta qué punto sería posible encontrar analogías entre el tango y el fado, particularmente en lo que se refiere a sus poéticas tradicionales. Vale aclarar que, debido a que esos ejercicios reúnen principalmente tangos y fados clásicos, es decir, anteriores al declive experimentado por ambos géneros pasada la segunda mitad del siglo XX, no tomaremos en consideración las composiciones posteriores, escritas durante las últimas décadas del siglo $\mathrm{XX}$ y comienzos

5 La cuestión del acompañamiento instrumental de los vocalistas en el tango y en el fado es bastante más compleja y ha presentado variaciones a lo largo del tiempo. De todas maneras, a grandes rasgos podemos afirmar que la guitarra es uno de los instrumentos más asentados en ambas trayectorias. En el caso del fado, en realidad, el fadista suele cantar acompañado por una o más guitarras portuguesas — en portugués, guitarra, conformada por seis cuerdas dobles - y guitarras clásicas — viola - , a las que se puede sumar una guitarra bajo — viola baixo - Para tener una noción más acabada sobre este asunto remitimos a Castelo-Branco (2000: 76-80), a Vieira Nery (2004: 96-99), a Sucena (2008: 79-88) y a Gouveia (2013: 277 283). En cuanto al tango cantado, surgido en 1917, en sus comienzos contó de manera casi exclusiva con el acompañamiento de guitarras, práctica que se mantuvo vigente durante todo el período del tango canción. La incorporación del cantante en una orquesta típica es posterior; a mediados de los años veinte aparece la figura del estribillista, que recién a fines de los treinta se transforma en cantor de orquesta con un rol de mayor envergadura. 
del siglo XXI. A causa de motivos que expondremos a lo largo del trabajo, creemos que un punto de conexión radica en ciertas similitudes en la vivencia de las ciudades gestantes del tango y el fado - Buenos Aires y Lisboa- y el modo en que ambas son poetizadas por ellos. Por esta razón, en el presente artículo adoptaremos el enfoque geocrítico, esbozado por Bertrand Westphal, que tiene como objeto "las interacciones entre los espacios humanos y la literatura" y que asume como uno de sus principales desafíos "contribuir a la determinación/indeterminación de las identidades culturales" (2015: 35). En sintonía con estos lineamientos, nuestra meta a largo plazo consiste en desentrañar de qué manera el tango y el fado traducen la dimensión imaginaria de sus respectivas ciudades (Westphal, 2015: 39). Para ello abordaremos las interacciones entre Lisboa y el fado y Buenos Aires y el tango, atendiendo especialmente a las semejanzas y las diferencias entre ambos procesos.

En este contexto, el propósito de este artículo es comenzar a sopesar las letrísticas del tango y del fado del siglo XX como poéticas portuarias, y la ciudad por ellas imaginada como espacio heterotópico (Foucault, 2008; Westphal, 2015) fundante de su identidad. En cuanto al primer aspecto, partimos de la hipótesis de que la ciudad puerto se configuraría como una matriz de sentido en el entramado poético de estas canciones, susceptible de convertirse en una categoría de análisis que supera lo territorial, pues por su propia definición el puerto es puente y pasaje por el que avanza el influjo del río y del mar, que modela el suelo urbano y, consecuentemente, la relación del sujeto con el espacio. En segunda instancia, nos detendremos en algunos aspectos poéticos del tango y el fado relacionados con el espacio, que permiten acercarnos a la configuración heterotópica de Buenos Aires y de Lisboa.

Hasta el momento no hemos encontrado en el medio académico estudios que indaguen en las posibles convergencias entre el tango y el fado. En otros ámbitos, ${ }^{6}$ algunos artistas, aficionados y estudiosos han comentado

6 De hecho, los comentarios que expondremos a continuación sobre las semejanzas entre el tango y el fado provienen de entrevistas a artistas, como es el caso de Karina Beorlegui, o de estudios más amplios, focalizados en otros aspectos de estos géneros, como el exhaustivo libro sobre el fado Ao fado tudo se canta? (2013), publicado por el fadista Daniel Gouveia. 
ciertas afinidades poéticas entre dichos géneros y han señalado su condición de haberse gestado en ciudades puerto (Beorlegui, 2013 y 2018; Gouveia, 2013; Vera Sepúlveda, 1999). No obstante, estos argumentos han sido presentados de forma hipotética en el marco de otras discusiones, como fruto de lecturas agudas pero carentes de ulterior desarrollo, de manera que, a nuestro criterio, sería interesante que surgieran trabajos académicos que vincularan y profundizaran estas dos premisas. Es esta vacancia la que intentaremos empezar a subsanar en el presente artículo.

Por ejemplo, al ser interrogada sobre las similitudes entre el tango y el fado, la mencionada artista Karina Beorlegui, quien se ha definido como "cantante de música de puertos" (2005), recurre a la imagen de Lisboa y Buenos Aires como espejos, al tiempo que subraya la coincidencia en los temas de sus poéticas y en su bohemia enraizada en lo local:

\footnotetext{
Son poéticas con mucho que ver, como un encuentro Borges-Pessoa. Ambas tienen una bohemia muy local, muy de pertenencia. La rua, el barrio. Caminando las calles de los barrios de Lisboa, uno podría encontrarse un bandoneonista tocando un tango. No ocurre, pero no estaría fuera de lugar. Esta cosa de las músicas de puerto, de un río ancho que desemboca en el mar, tienen muchas similitudes en ese sentido. Lisboa y Buenos Aires, fado y tango, nacieron en los puertos para la misma época y tienen este $\mathrm{ADN}$ en común que es la nostalgia y la saudade (Beorlegui, 2018)
}

Beorlegui insiste en el puerto como origen de ambos géneros y sobre todo como matriz simbólica cuya polivalencia - paso, desarraigo, encuentro, mixtura (Beorlegui, 2013) - se traduce en la composición poética del tango y del fado. Como explican María Emilia Sandrín y Nicolás Biangardi, "los espacios portuarios no se limitan a ser uno de los marcos donde se desarrollan las actividades de los hombres en sociedad", puesto que los espacios se constituyen como "estructuras sociales que condicionan a las otras estructuras que conforman la sociedad" (2015: 8). Pero ese condicionamiento fluctúa a lo largo del tiempo. Claramente la influencia ejercida por los puertos de Lisboa y Buenos Aires en el tejido urbano durante las épocas en que se desarrollaron estas músicas — siglos XIX y principios del XX— guarda bastante distancia 
con el papel que actualmente desempeñan, en el que prevalece el intercambio turístico y comercial. Basta recordar que en aquellos tiempos todavía funcionaba el tránsito marítimo de pasajeros como principal opción para los viajes transatlánticos y este era, entonces, el medio por el que llegaban los inmigrantes a Buenos Aires o los viajeros a Lisboa. De esta manera, el puerto tenía una injerencia en el entramado social mucho más directa de la que posee en la actualidad.

Ahora bien, más allá de que reconozcamos la relevancia de la actividad portuaria ejercida a finales del siglo XIX y principios del siglo XX en Buenos Aires y en Lisboa, ¿sería pertinente hablar de las letrísticas del tango y del fado como poéticas de la canción portuaria?, ¿"lo portuario" es suficientemente relevante como para constituirse en categoría especificadora, dentro de la más amplia clasificación de "canción popular urbana"? Procuraremos esbozar un acercamiento inicial a posibles respuestas.

En primer lugar, coincidimos nuevamente con Sandrín y Biangardi, quienes recalcan las dificultades para lograr una definición precisa de las ciudades puerto, tan diversas en su acontecer. No obstante, como ellos mismos advierten, esas ciudades lograron constituirse como tales merced al movimiento de bienes y de personas generado por el puerto. Por ese motivo, aun cuando el crecimiento posterior del asentamiento urbano haya podido relegar el rol preponderante que el puerto tenía en el pasado (Sandrín y Biangardi, 2015: 8-9) o se haya opacado su visibilidad, lo cierto es que este fue el cimiento sobre el que originalmente se establecieron Buenos Aires y Lisboa. Por consiguiente, la influencia del puerto permanece en la trama misma de la urbe.

En segundo lugar, consideramos que lo portuario también se irradia sobre la cultura de la estructura social urbana a la que modela. En este sentido, Patricio Landaeta Mardones, Braulio Rojas Castro y Alexis CandiaCáceres han pensado en las implicancias culturales de algunos puertos latinoamericanos. En Geofilosofía de la ciudad puerto sostienen que, si en la época colonial la corona se valía de las ciudades latinas para imponer patrones de costumbres, pensamientos y afectos, puertos como Buenos Aires, El Callao o Valparaíso “contribuyeron a la «contaminación» de ese orden 
forjado por la empresa de puesta en policía de los territorios", por medio del florecimiento de una " "cultura menor», si se define por tal a la que crece en los límites de la escritura oficial del espacio habitado" (2016: 8). De esta manera, dichas ciudades puerto se transformaron en espacios de contagio, donde "los colonizados gestaron su propia autonomía popular" (Landaeta Mardones, Rojas Castro y Candia-Cáceres, 2016: 8). El tango constituiría un ejemplo perfecto de dicho proceso. A pesar de la diferencia de contexto, algo similar puede decirse del fado y de Lisboa, pues al ser esta ciudad una de las puertas de acceso a Europa, ha estado expuesta a la circulación de gente de distintos continentes. Consecuentemente, ante la amenaza constante de disolución, se erigió en un foco de resistencia cultural.

Los mencionados autores también se han planteado la pertinencia de lo portuario como categoría estética, en el marco de un proyecto de investigación consistente en el análisis de las literaturas portuarias del litoral subpanameño, sobre todo de Valparaíso. Ellos proponen una definición de literatura portuaria como regional, entendiendo este último concepto en un sentido que sobrepasa la dimensión territorial. Así, las literaturas surgidas en los puertos del Litoral subpanameño corresponderían a una literatura regional definida por la relación con el mar más que con la tierra (Landaeta Mardones, Rojas Castro y CandiaCáceres, 2016 y Chandía Araya, 2016).

Sin embargo, en lo concerniente al tango y al fado, sería problemático definir la poética portuaria como regional, porque esta categoría en Latinoamérica ha estado tradicionalmente empleada para hacer referencia a literaturas producidas en el interior de los países o consagradas a representar la vida en regiones provinciales o campestres, a menudo en contraposición a la vida urbana o metropolitana (Schmidt-Welle, 2012: 115). Es viable en el caso de Valparaíso, dado que no es una ciudad capital, pero no resulta del todo adecuado para Buenos Aires y Lisboa, porque estas sí son capitales nacionales. En cambio, otras conceptualizaciones sobre los puertos expresadas por los mencionados investigadores sí nos pueden ayudar a pensar en las huellas portuarias reconocibles en las ciudades del fado y del tango: la amalgama de procedencias y de clases sociales, el entrecruzamiento topográfico sin 
planificación previa, la emergencia de una contracultura y la configuración de un espacio de resistencia, la convergencia de elementos heterogéneos, la tensión entre el encuentro y el desencuentro interpersonal, entre otras características. En el presente trabajo, entonces, queremos comenzar a analizar cuáles de estos rasgos cobran especial fuerza en lo urbano portuario y de qué manera se trasponen en las poéticas del tango y del fado.

Por otra parte, querríamos aclarar que la denominación "género portuario" ha sido empleada en relación con el tango y con el fado por Miguel Ángel Vera Sepúlveda, quien ha formulado una teoría sobre el origen de cuatro géneros musicales latinoamericanos. Se trata de músicas surgidas hacia finales del siglo XIX en cuatro influyentes puertos: el tango rioplatense, la ranchera de Veracruz (México), el vals porteño de Valparaíso (Chile) y el Valsecito criollo de El Callao (Lima, Perú). Este autor postula que los mencionados géneros, nacidos en los puertos más importantes de la zona, recibieron el influjo del fado portugués a través del comercio marítimo con Europa, en cuyas tripulaciones era notable la presencia de marinos portugueses (Vera Sepúlveda, 1999: 232). A pesar de que esta teoría no fue posteriormente desarrollada, los argumentos esgrimidos por Vera Sepúlveda dan cuenta de la posibilidad de realizar un abordaje comparatista de estos géneros. En efecto, para fundamentar la influencia del fado en el tango, la ranchera, el vals porteño y el valsecito criollo, el crítico rescata: un fondo literario y temático común, determinadas conexiones musicales entre el fado y el soporte musical primigenio de estos géneros, ${ }^{7}$ y el hecho de que todas estas músicas latinoamericanas se gestaran en los puertos más importantes para el comercio marítimo mercantil entre las últimas décadas del siglo XIX y las primeras del siglo XX (Vera Sepúlveda, 1999: 230-233). En cuanto a lo poético, Vera Sepúlveda sostiene que estos géneros han tenido "la capacidad de sintetizar los sentimientos inherentes a la vida los puertos marítimos" (1999: 230), entre los cuales enumera el

7 Vera Sepúlveda sostiene que originalmente no hay tanta distancia musical entre todos estos géneros como podría parecer a primera vista, pues en las formas primarias de cada manifestación ciertas armonías básicas presentan un uso común de las escalas naturales, sobre todo en sus tonos más agudos (cfr. 1999: 232). 
abandono, los celos, los falsos amores o los amores imposibles, la partida del ser amado, etc. (230 y 233). Estas afirmaciones, en consonancia con la postura de Beorlegui, implicarían que ciertos tonos emocionales asumidos por la voz lírica y performática ${ }^{8}$ del tango y del fado estarían vinculados con una vivencia poética de un espacio particular: la ciudad puerto.

Además, Vera Sepúlveda añade que en el folklore de México, Argentina, Chile y Perú nunca había existido la temática de marginalidad urbana que caracteriza al género portuario y que se distancia de los contenidos campestres, donde predomina la nostalgia por el paraíso perdido y la exaltación de los paisajes agrícolas (1999: 230). Aunque, en realidad, en lo que respecta al tango debemos aclarar que sí existía previamente una especie de folklore urbano que incorporaba temáticas y personajes marginales, es cierto que estos nuevos géneros latinoamericanos se diferencian de las canciones de tierra adentro de los respectivos países.

En función de lo expuesto hasta el momento, consideramos que lo portuario como categoría estética podría ser pertinente para comprender las letrísticas del tango y del fado y su forma de construir la ciudad imaginada. Yi Fu Tuan sostiene que la cosmovisión de un pueblo, "a menos que se derive de una cultura extranjera, se forma necesariamente a partir de los factores preponderantes de la realidad física y social" de aquel (2007: 112). Nosotros consideramos que la forma de percibir y de comprender el entorno por parte de un grupo humano responde a un proceso más complejo, en el que pueden confluir variables diversas. Y la trasposición ${ }^{9}$ en la poesía popular de esas

8 Siguiendo a Taylor, utilizamos el término performático, en lugar de performativo, como adjetivo de la palabra performance. El objetivo de Taylor es establecer una diferencia entre el concepto de performativo desarrollado por John Langshaw Austin y el de performance. El primero designa a ciertos actos de lenguaje que efectivamente se convierten en un hecho susceptible de implicancias legales; es decir, ocurre dentro de un contexto con circunstancias y convenciones específicas. Por el contrario, lo performático no constituye un acto legal (cfr. Taylor, 2012: 111-112). Por voz performática entendemos la voz de la puesta en escena, los matices propios que se funden o se superponen con el texto en la interpretación de cada cantor o fadista.

9 Coincidimos con Rosalba Campra cuando afirma que el tango - y, añadimos, la poesía popular en general - "registra la realidad según mecanismos que no son los del reflejo sino los de la trasposición” (cfr. 1996: 35). 
representaciones, intuiciones o reinterpretaciones de la realidad añade, a su vez, otras complejidades. Hechas estas aclaraciones, nos atrevemos a postular que es posible que determinadas afinidades o posibilidades de diálogo entre las poéticas del tango y el fado hayan sido estimuladas por factores comunes presentes en sus ciudades de gestación, facilitados por su condición de ciudades portuarias. Un acercamiento temático a estos géneros no bastaría para dar cuenta de su poetización del espacio urbano; por el contrario, sostenemos que puede ser más fructífero sondear la relación de la voz con el lugar y la construcción de una subjetividad localizada. Por ese motivo, rastrearemos en ambas letrísticas algunos primeros indicios de la relación del sujeto lírico con el espacio.

\section{VOZ Y CIUDAD}

Una de las coincidencias más notables entre el tango y el fado es que tanto en sus letras como en la performance se manifiestan como géneros enfáticamente localizados, anclados en una geografía precisa: Lisboa y Buenos Aires respectivamente, o alguno de sus barrios. Como contracara de la diversidad y la circulación características de todo puerto, dichas ciudades se erigen simultánea y paradójicamente en tierra firme de intensa carga identitaria. En el caso del tango es más frecuente la evocación de los barrios que de la ciudad en su conjunto, aunque esta también tiene cabida en algunos tangos célebres como "Buenos Aires" (Romero y Jovés, 1923), "La canción de Buenos Aires" (Romero y Maizani / Cúfaro, 1933) o "Mi Buenos Aires querido" (Gardel y Le Pera, 1934). En el fado, en cambio, la alusión a la ciudad en su conjunto es tan habitual como la referencia a los barrios Mouraria, Alfama o Bairro Alto.

Al analizar la relación entre Lisboa y el fado, Richard Elliott sostiene que este género "a través de la combinación de palabra, música y gesto que se solidificó como su estilo musical, performatiza el lugar de una manera muy particular, convocando una mitología que intenta trazar la ciudad del 
pasado recordada e imaginada a través de una poética de la evocación"10 (Elliott, 2016: 65). Otro tanto podríamos decir del tango. En efecto, la ciudad y los barrios, esto es, los espacios más cantados por el tango y por el fado, no responden simplemente a una construcción poética, sino también a una performatización ${ }^{11}$ del espacio en la que intervienen fundamentalmente la voz, el cuerpo y los gestos del artista, además de la música y la puesta en escena. Así, si por un lado tenemos a la cosmopolita Amália Rodrigues que vestida de negro o con los tradicionales xailes portugueses representaba a Lisboa en todo el mundo, también hubo otros fadistas más amalgamados con la ciudad, como Alfredo Marceneiro — referente y defensor del estilo del fado más castizo, previo a la profesionalización - o incluso con un barrio específico, como Fernando Farinha, conocido como el "miúdo da Bica"12 (cfr. Elliott, 2016: 68), debido al barrio lisboeta con el que se lo identificaba. En el caso del tango, la propia figura de Carlos Gardel sintetiza la transformación del cantor nacional en cantor urbano de tangos: ${ }^{13}$ cambia la vestimenta, se calza el traje, forja un modo de cantar el nuevo género y modela una gesticulación ad hoc. Convertido ya en estrella internacional, varios tangos que aparecen en sus películas filmadas en el exterior contribuyen a la consagración de Buenos Aires como espacio del tango, muchas veces teñido por la nostalgia de la

10 La traducción es nuestra.

11 Aquí la palabra performance y su derivado performatizar ponen de manifiesto la polivalencia del concepto, por cuanto subrayan la interacción de la voz y del cuerpo del cantante con el texto durante la interpretación artística. En su estudio sobre la performance, Simon Frith se refiere a ella como un proceso social, entre cuyos signos comunicativos destaca el rol de "la retórica de los gestos", esto es, "los movimientos y los signos corporales (incluyendo el uso de la voz)" (2014: 360). Además, Frith también se ocupa de las relaciones del cuerpo durante la performance con elementos externos, entre ellos la ropa, a la que define como "el modo de hablar del cuerpo" (cfr. 381 y 382 ).

12 Bica es un barrio de Lisboa.

13 El Cantor Nacional fue, de cierto modo, el heredero del gaucho cantor, ya urbanizado en los arrabales de la ciudad, quien acometió la tarea de difundir en ella los ritmos camperos y las historias de la tierra (Russo, 2011: 31). Carlos Gardel fue originalmente cantor nacional y comenzó su carrera artística en dúo con el cantor José Razzano. En su repertorio había canciones criollas, zambas, estilos, cifras, valses. Fue recién en 1917 que Carlos Gardel entona su primer tango, "Mi noche triste", y a partir de ahí comienza progresivamente a incorporar este nuevo género, hasta transformarse en el cantor de tangos modélico. 
lejanía: "Volver" en el film El día que me quieras (1935), "Arrabal amargo" en Tango bar (1935) o "Melodía de arrabal" en la película homónima (1933).

El tango y el fado también modelan el espacio al darle o consagrarle una voz, gesto que se hace consciente en el plano poético de distintas maneras. En el tango una de ellas es a través de la figura del cantor del barrio o del arrabal, sintagma en el cual la preposición de designa tanto la proveniencia u origen del personaje como una idea de mutua pertenencia: 14 "Soy aquel cantor del arrabal,/ jilguero criollo que pulsó/ la humilde musa de percal" (Cadícamo y Cobián, "El cantor de Buenos Aires", 1936). El cantor pertenece al barrio y, de algún modo, también lo posee. Ambos significados se actualizan y se potencian en el cantor del arrabal, que se constituye en tal y forja su identidad en función del espacio, al cual a su vez le ofrenda su voz: "Mi barrio reo,/ mi viejo amor,/ oye el gorjeo,/ soy tu cantor" (Navarrine y Fugazot, "Barrio reo", 1927). El sujeto se amalgama con su lugar, de modo que los límites entre uno y otro se difuminan.

En el fado encontramos ejemplos de atribución de una voz a un lugar específico, lo cual redunda en una personificación del espacio, como la ciudad de Lisboa: "Sempre que Lisboa canta/ Não sei se canta/ Não sei se reza/ A sua voz com carinho/ Canta baixinho/ Sua tristeza" (Rocha y Nazaré, "Sempre que Lisboa canta"). ${ }^{15}$ O el río Tajo: "É a voz do Tejo/ Que me traz tanta saudade/ Desse meu desejo/ Que deixei na despedida/ É a voz do Tejo/ A voz do fado e da cidade/ Que foi minha mãe/ Minha madrasta e minha vida" (Avelar Pinto y

14 En el Diccionario de la Real Academia Española aparecen ambas acepciones de la preposición $d e$. La primera acepción denota posesión o pertenencia, mientras que la tercera señala la proveniencia de algo (cfr. RAE).

15 Debemos hacer algunas aclaraciones con respecto a la forma de citar las letras de los tangos y de los fados. Al transcribir los versos de un tango hemos colocado entre paréntesis al letrista y al compositor, junto con el año de composición o de estreno de la pieza. Hemos extraído los datos de la antología de Eduardo Romano (1993) o de las partituras. En cuanto a los fados, la situación es distinta, porque las antologías no suelen consignar el año de composición de la pieza. Por ende, simplemente hemos referido al letrista y eventualmente al compositor. Es sabido que la composición musical en el fado presenta algunas fluctuaciones, dado que es común que una misma melodía haya sido utilizada con distintos versos. La mayoría de los fados han sido extraídos de la antología de Daniel Gouveia y Francisco Mendes (2014) y de Vítor Pavão dos Santos (2014). 
Kyao, "Voz do Tejo"). Estos textos, como los tangos antes citados, dan cuenta de una particular proximidad entre el sujeto y el espacio que habita o al que se siente ligado; la separación entre una y otra entidad pierde nitidez.

Por otra parte, al consagrarles o atribuirles una voz a los espacios exteriores - la ciudad o el barrio-, el tango y el fado se apropian de ellos y los internalizan, pues estos adquieren significaciones y notas propias de los lugares de intimidad. Si reflexionamos sobre las percepciones auditivas surgidas en los lugares exteriores y abiertos, es más probable que las asociemos con determinados ruidos y sonidos específicos — de autos, de sirenas, del ajetreo propio de la calle-, que con voces subjetivas. En nuestros recuerdos o pensamientos, las voces se hacen más presentes en relación con los espacios interiores que con los exteriores, donde la voz se pierde en la inmensidad y donde, como dijimos, predominan otra clase de sonidos. En su clásico estudio sobre el espacio Gaston Bachelard se detiene en las voces del interior de la casa del pasado, perdida pero recordada, donde resuenan los ecos de las voces de otras épocas (Bachelard, 2000: 70). Cuando el tango y el fado identifican el espacio exterior con una voz, de alguna manera, entonces, lo resignifican como un espacio de intimidad. De esta forma, así como se esfuman las fronteras entre el sujeto y el espacio, también se subvierten los límites entre lo privado y lo público, entre lo íntimo y lo colectivo.

Otra concurrencia entre el tango y el fado estriba en el hecho de que la ciudad cantada por ellos suele estar detenida en el tiempo, de modo que la ficcionalización del espacio responde más a una cartografía del recuerdo que a una representación. El fado con frecuencia admite esta operación, como en "Vielas d'Alfama": "Vielas d'Alfama, ruas da Lisboa antiga/ Não há fado que não diga coisas, do vosso passado" (Ribeiro/De Sousa). Otro tanto sucede en "Fado da Madragoa", donde desfilan personajes ya poco habituales para la época en que se escriben estos versos, como las religiosas o las vendedoras de pescado — varinas—: “Ó Madragoa das bernardas e das trinas/ Dos pescadores, das varinas... da tradição/ És a Lisboa que nos fala doutra idade/ Desses tempos da cidade... que já lá vão" (Galhardo y Ferrão, "Fado da Madragoa"). O también en el afamado "Lisboa antiga", donde se 
deja constancia de que se le está cantando a la ciudad de otro tiempo:

Olhai senhores, esta Lisboa d'outras eras

Dos cinco reis, das esperas

E das toiradas reais

Das festas, das seculares procissões

Dos populares pregões matinais

Que já não voltam mais

(Galhardo, Do Vale y Portela, "Lisboa antiga")

Otras veces el fado no explicita que se trata de un espacio de otra época, se hace evidente por sus habitantes o por los elementos extemporáneos que componen el paisaje:
Ai Mouraria
Dos rouxinóis nos beirais
Dos vestidos cor de rosa
Dos pregões tradicionais
Ai Mouraria
Das procissões a passar
Da Severa, a voz saudosa
Da guitarra a soluçar
(Valerio y Do Vale, “Ai Mouraria")

Los pregones, las procesiones y la Severa ${ }^{16}$ mencionados en los versos precedentes son revividos en numerosos fados - "Eu nasci na Mouraria" (Conde de Sobral), "Foi na velha Mouraria" (Teles y Duarte), entre otrosEspacio, tiempo, fantasía y memoria se confunden en la evocación de una ciudad imaginada, fundamentalmente la de aquella donde se asentaron los orígenes míticos del fado. En el tango sucede algo similar, porque las imágenes visuales y sonoras presentes en las descripciones o las alusiones al barrio colaboran con la construcción de un imaginario urbano anacrónico:

16 Nos referimos a la mítica fadista Maria Severa Onofriana, nacida en Lisboa en 1820 y fallecida a la corta edad de veintiséis años. Su historia, que reúne varios clichés románticos - supuesto ejercicio de la prostitución, amores con aristócratas, personalidad avasallante, muerte prematura - se convirtió en una leyenda de los comienzos del fado en pleno siglo XIX. 
Un pedazo de barrio, allá en Pompeya,

durmiéndose al costado del terraplén.

Un farol balanceando en la barrera

y el misterio de adiós que siembra el tren.

Un ladrido de perros a la luna.

El amor escondido en un portón.

Y los sapos redoblando en la laguna

y a lo lejos la voz del bandoneón.

(Manzi y Troilo, "Barrio de tango", 1942)

Por ejemplo, la presencia del farol es recurrente, prácticamente un cliché, en algunos tangos donde se describe o se menciona a Buenos Aires o al barrio, ${ }^{17}$ aunque a fines de los años veinte ya no era muy frecuente encontrarlos en las calles de dicha ciudad. De cierto modo, el barrio se presenta como un ámbito de resistencia ante el transcurso del tiempo y ante la modernidad arrasadora:

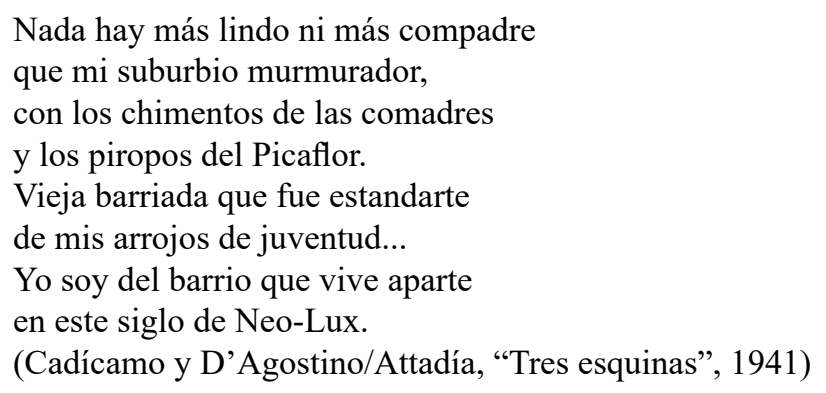

En este sentido, el detenimiento en el tiempo de los barrios en el tango y en el fado muchas veces implica, paradójicamente, la exaltación de las características rurales persistentes en estos medios urbanos, ámbito aquel cuya fisonomía se modifica más lentamente que la de la ciudad. Este gesto conlleva, por momentos, una cierta superación de la antinomia campo-ciudad, debido a que la urbe conserva en su interior algunos rasgos camperos y ese aspecto también es celebrado por estos géneros. Por consiguiente, la experiencia

17 Algunos ejemplos son "Mi Buenos Aires querido" (Le Pera y Gardel, 1934), "Silbando" (González Castillo y Piana/Castillo, 1925), "Recostado en un farol" (Aguilar y Mottolese, 1928), "Farol” (Expósito, Homero y Expósito, Virgilio; 1943). 
urbana así concebida se vuelve híbrida; no consiste en una negación absoluta de la vida campestre.

Hay, sin embargo, una diferencia notoria en el modo en que ambas poéticas trazan el mapa urbano. En efecto, en una parte de la letrística del tango de las décadas de los veinte y los treinta, la ciudad está polarizada: el barrio y el centro se contraponen como dos espacios antagónicos, sobre todo en relación con la figura de las milongueras ${ }^{18}$ —aunque también con respecto a los compadritos- El barrio es lugar de origen de las milonguitas, "el suburbio-paraíso perdido" (Ulla, 1982: 36), pero a la vez el espacio de un futuro predecible y sin crecimiento económico; mientras que el "el centro- la perdición", donde están los cabarets, es el espacio donde la mujer se transforma en milonguera. Esta elección suele ser motivo de reproche en las letras de tango. La contraposición centro-arrabal se complementa con aquellas letras que idealizan el barrio. La ciudad del tango, por ende, se caracteriza por la discontinuidad; es decir, el paso de un lugar a otro no solo se experimenta, sino que además transforma al sujeto (cfr. Mongin, 2006: 23). ${ }^{19}$ Posteriormente, en la letrística del tango el dualismo ciudad-arrabal se diluye al acercarse la década de los treinta y solo permanece la celebración del arrabal.

Por el contrario, en el fado no parece registrarse un antagonismo similar. El mapa urbano responde más bien a un patchwok, donde en ocasiones los distintos barrios se disputan el podio del más fadista — "Fado da Madragoa" (Galhardo y Ferrão), "Ronda dos bairros" (Dos Santos y Freitas),

18 El personaje femenino de la milonguera o milonguita fue bastante popular en el tango canción entre sus comienzos y mediados de los años treinta. Tal como fue cantada por el género, podríamos definirla como la muchacha que, seducida por la posibilidad de mejorar su situación socioeconómica, abandona su barrio para trabajar como copera y bailarina en los cabarets del centro de la ciudad. Según el tango, la transformación de esta mujer se registra en su desplazamiento del barrio al centro, en vestimenta - cambia el vestido de percal por el de seda - en su aspecto — se tiñe de rubia y se corta el pelo - y en su modo de hablar y de comportarse a la francesa. A pesar de que fuera Samuel Linning quien popularizara el nombre del personaje gracias a "Milonguita" (1920), esta temática ya se registra como tal en dos letras anteriores: "Flor de fango" y "Pobre Paica" de Pascual Contursi.

19 Oliver Mongin explica que cuando en una ciudad reina lo continuo, el paso de un lugar a otro no se advierte. El sujeto puede desplazarse por esa ciudad sin notarlo. Por el contrario, en una ciudad discontinua se experimenta el paso de un lugar a otro (Mongin, 2006: 23). 
"Magia do fado" (Soares Pereira y Dos Santos/Rodrigues)—. A pesar de esta competencia, las descripciones de los barrios suelen ser bastante similares entre sí: callecitas, fado, saudade son los componentes predominantes. Al margen de las diferencias en el diseño de la Lisboa del fado y de la Buenos Aires del tango, en lo que sí coinciden ambos géneros es en un trazado urbano caracterizado por los pliegues, es decir, por espacios en tensión (Mongin, 2006: 40-41), fundamentalmente entre el adentro y el afuera, lo privado y lo público, el pasado y el presente, lo imaginado y el referente real.

\section{CIUDADES HETEROTÓPICAS}

Así las cosas, Buenos Aires y Lisboa, ya sea invocadas en su totalidad o en sus diversos barrios, se transforman en heterotopías y en heterocronías, en lugares otros y anacrónicos con respecto a sus referentes, definidos por Michel Foucault como "impugnaciones míticas y reales del espacio en que vivimos" (2008). En efecto, este procedimiento de mitificación y de autoconstrucción escenográfica es el que llevan al cabo el tango y el fado al recrear sus propias cartografías y coordenadas espaciotemporales de Buenos Aires y de Lisboa. Ambos géneros dejan en evidencia que son conscientes de su artificio, que el espacio evocado por ellos —el barrio, la ciudad - es una invención o, por lo menos, el recuerdo de algo que ya no existe. Por ejemplo, el fado "Antigamente" (De Brito y Proença) explicita que la Mouraria tan celebrada por otros fados es tan distinta de la real y contemporánea, que lo único que resta de su antigua gracia se encuentra en la capillita de la Senhora da Saúde: 


\author{
E a Mouraria \\ Que perdeu em tempos idos \\ A nobreza dos sentidos \\ E o poder de uma virtude \\ Salvou ainda \\ Toda a graça que ela tinha \\ Agarrada à capelinha \\ Da Senhora da Saúde \\ (De Brito, "Antigamente")
}

Los cambios topográficos y la distancia entre la ciudad real y la ciudad cantada son advertidos por el fado sobre todo en relación con el barrio de Mouraria, lo cual atestiguan otros fados: "Bairro eterno" (Vieitas), "A senhora Mouraria" (Farinha y Correia), "O que sobrou de Mouraria" (Nobre, Fonseca, Bracinha, D’Oliveira). Esta circunstancia está motivada por el proceso de modernización ejecutado por el Estado Novo entre los años treinta y sesenta, que afectó la tradicional fisonomía de este barrio. Consecuentemente, observamos nuevamente que la memoria y la imaginación al servicio de las topografías poéticas del tango y del fado pueden traducirse en una forma de resistencia no solo ante la modernidad, como veíamos antes, sino fundamentalmente ante aquellos cambios que ponen en jaque la identidad del espacio habitado o frecuentado.

De manera similar, el tango también admite que la Buenos Aires o los barrios poetizados por él conforman heterotopías. Es ilustrativo "Yuyo verde", el cual advierte que el paisaje descripto tiene un anclaje intragenérico; constituye una metarreferencia, puesto que su referente es un espacio construido por la poética del género en vez de un lugar real: "un farol, un portón, igual que en un tango" (Expósito y Federico, 1944). Como explica Julio Schvartzman, este juego de inclusiones es naturalizado por el auditor dado que "el tango ha instalado, con inusitada potencia, su propio mito" (2014: 164), en el cual el espacio imaginado ocupa un lugar eminente. En "Yuyo verde" ese lugar es la escenografía del recuerdo de un amor perdido: 


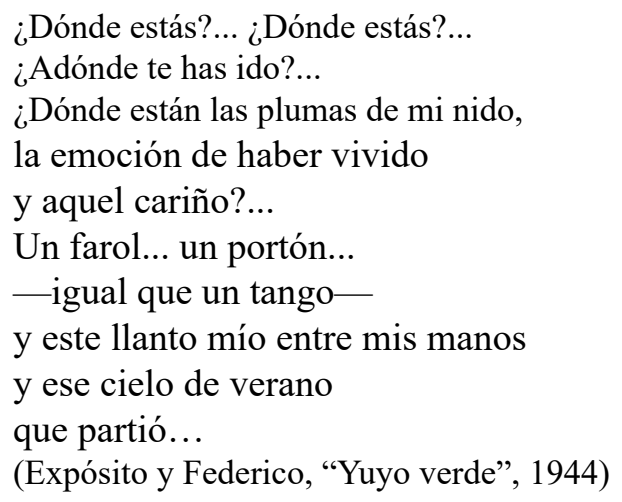

Asimismo, por mencionar otro ejemplo, el tango "Sur" reconoce que el paisaje cantado, al igual que la antigua vida del sujeto que lo evoca y con la que el barrio se amalgama simbióticamente, ya solo existen en la memoria: "San Juan y Boedo antiguo, cielo perdido/ [...] pesadumbre de barrios que han cambiado/ y amargura del sueño que murió" (Manzi y Troilo, 1948). En consecuencia, tal como se manifiesta en las dos obras recién citadas - "Yuyo verde" y "Sur" - registramos en la letrística del tango un dinamismo similar al que encuentra Elliott en el fado:

Ya sea que se refieran a la ciudad como un todo o a uno de los barrios más asociados con el género - Alfama, Mouraria, Bairro Alto y Madragoa - las letras de los fados proveen topografías de lo perdido que ubican a la ciudad como objeto de deseo o de ausencia, o como trasfondo de otro objeto perdido, recordado o deseado ${ }^{20}$ (Elliott, 2016: 66)

La dimensión heterotópica de la Buenos Aires del tango y de la Lisboa del fado se trasluce, además, en que el espacio es simultáneamente objeto y sujeto, idea que en cierta manera hemos adelantado al referirnos al fado "Sempre que Lisboa canta". En lo que concierne a la ciudad, la analogía entre esta y el individuo tiene una antigua raíz en la cultura occidental. Nicole Loraux indica que en muchos textos oficiales de la polis griega la ciudad asumía la función de sujeto. Además, explica que en la obra de Tucídides la ciudad y el

20 La traducción es nuestra. 
individuo obedecen a los mismos grandes afectos y que, para Platón, aquella era un sujeto, porque se le podía atribuir un alma (Loraux, 2008: 77-78).

La subjetividad asumida por los espacios en el tango y en el fado se manifiesta de distintas formas; una de ellas es el reconocimiento de que poseen una voz propia, según hemos comentado previamente. Otra modalidad mucho más frecuente en ambos géneros es la constitución del espacio como interlocutor, lo cual consiste en una forma de prosopopeya por cuanto supone tratar los objetos como sujetos al atribuirles la capacidad de escuchar ${ }^{21}$ (Mayoral, 1994: 279). Atendiendo a la tradición retórica, José Antonio Mayoral señala que este recurso, también llamado "personificación" y "fingimiento o hechura de persona" (1994: 278) adquiere "su sentido más pleno y verdadero cuando tales «personas» o «realidades personificadas»" se fingen "partícipes de un acto comunicativo, tanto en la condición de emisor como de receptor" (Mayoral, 1994: 279-280).

En el tango y en el fado esta forma de prosopopeya, según la cual un objeto inanimado es transformado en destinatario, es un recurso habitual en relación con el lugar, sea este la ciudad o uno de sus barrios. Podemos citar algunos ejemplos de la orilla americana, como "La canción de Buenos Aires" (Romero y Cúfaro/Maizani, 1933), "Mi Buenos Aires querido" (Le Pera y Gardel, 1934), "Almagro" (Diez y San Lorenzo, 1930), "Barrio pobre" (García Jiménez y Belvedere, 1926), "Barrio reo" (Navarrine y Fugazot, 1927), "San José de Flores" (Gaudino y Acquarone, 1936), "Adiós arrabal" (Lenzi y Baüer, 1930), “Arrabal amargo" (Le Pera y Gardel, 1935), "Anclao en París" (Cadícamo y Barbieri, 1931), "Melodía de arrabal" (Le Pera / Battistella y Gardel, 1932), entre tantos otros. El género lusitano también acudió asiduamente a ese recurso, en fados como "Menina Lisboa" (De Brito), "Lisboa não sejas francesa" (Galhardo y Ferrão), "Sempre que Lisboa canta"

21 En efecto, en su libro Figuras retóricas José Antonio Mayoral explica que la prosopopeya pertenece a las figuras "que de algún modo canalizan el proceso de ficcionalización o simulación del propio acto de comunicación intratextual" (1994: 278) y consigue su mayor concreción en la "la atribución a las personas fingidas o a las cosas «personificadas» o fingidas «sub specie personae», de cualidades humanas y muy en especial de la capacidad de hablar/ escuchar" (1994: 279). 
(Rocha y Nazaré), "Fado da Madragoa" (Galhardo y Ferrão), “Ai, Lisboa" (Galhardo), "Lisboa antiga" (Galhardo y Do Vale/Portela), "Alfama" (Conde de Sobral), “Alfama velhinha” (Damas y Paião), por mencionar solo algunos.

El gesto de interpelar al espacio y de atribuirle figuradamente la capacidad de escuchar implica la ruptura de la barrera entre la esfera de lo material y la de lo humano; al acortarse la distancia entre una y otra, se establece una especie de continuidad. A veces la apelación se parece a los halagos o a los lamentos de un amante:

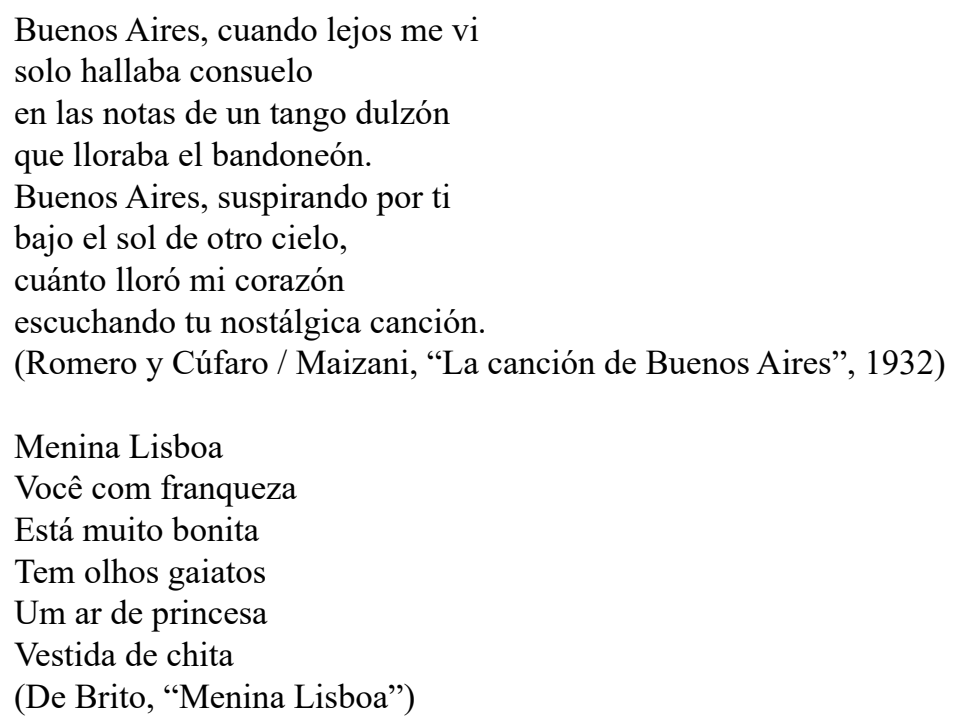

En el tango la intimidad entre sujeto y espacio se vuelve aún más estrecha, pues en ocasiones el espacio es incluso cómplice del sujeto, adquiere calidad de testigo:

Cuna de tauras y cantores, de broncas y entreveros, de todos mis amores.

En tus muros con mi acero yo grabé nombres que quiero.

Rosa, "la milonguita", era rubia Margot, en la primer cita [sic], la paica Rita me dio su amor.

(Le Pera / Battistela y Gardel, "Melodía de arrabal”, 1932) 
En algunas letras se va más lejos, por cuanto se produce una simbiosis sujeto-espacio. Por ende, más que habitar el lugar, a menudo el individuo se proyecta y se confunde con él, a tal punto que el espacio se desobjetiva y se desdibuja en el sujeto. Esta disolución percibimos en tangos como "Arrabal amargo" (Le Pera y Gardel, 1935), "Callejón” (Marcó y Grela, 1936), "Barrio reo" (Navarrine y Fugazot, 1927) y “Adiós arrabal” (Lenzi y Baüer, 1930). La apelación al destinatario se transforma en un desdoblamiento, se confunden los referentes, ya que hablar del tú es también hablar del yo:

\author{
Callejón, \\ a los dos bandeó el destino, \\ soy un triste peregrino \\ $\sin$ derrotero y $\sin$ fe. \\ Callejón, \\ vos serás mi confidente, \\ traigo doblada la frente \\ y a dónde voy yo no sé. \\ Como a mí \\ también te sangra una herida, \\ a vos la urbe te olvida \\ y ella ha olvidado mi amor. \\ Callejón, \\ por eso busco tu abrigo \\ lejos del mundo consigo \\ adormecer mi dolor. \\ (Marcó y Grela, “Callejón”, 1936)
}

Al proyectarse en el espacio, el individuo se identifica con él. Pero a veces esa proyección adquiere un sentido más oscuro, como en "Arrabal amargo", "San José de Flores" o "Adiós arrabal". El espacio manifiesta una connotación ambigua: la idealización tan habitual en otros tangos alterna con la descripción de un lugar abyecto. En "Arrabal amargo" este significado se explicita en una selección léxica que constituye una isotopía de la caída y del sufrimiento — “condena", "maldición", "torturan", "sombras", "clavao", "cruz" - . El barrio se transforma en un destino ineludible: 


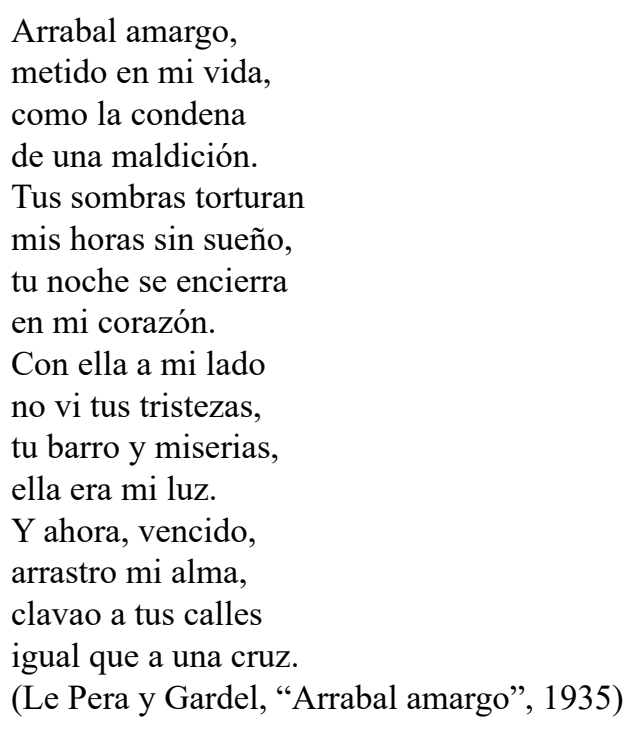

El personaje regresa al barrio derrotado, porque el afuera solo le deparó fracasos, idea que se repite en "Las cuarenta" (Gorrindo y Grela, 1937), "La casita de mis viejos" (Cadícamo y Cobián, 1932) o "Adiós arrabal" (Lenzi y Baüer, 1930). En esta dinámica de proyecciones, sujeto y espacio entran en una tríada al identificarse también con un destino. De manera semejante, este eje espacio-sujeto-destino se reitera constantemente en el fado, que suele jugar con la homonimia del portugués fado 'música' y fado 'destino'. "Eu nasci na Mouraria" es un ejemplo, entre tantas otras letras que acuden a esta polivalencia. Como hemos percibido en algunos tangos recién mencionados, aquí también sobrevuela la idea del espacio originario o habitado como determinante de un hado inexorable:

\footnotetext{
Se o destino está marcado

E só por ele vivemos

$\mathrm{O}$ bairro onde nascemos

Também lhe anda ligado

Não me sinto mal fadado

Nem maldigo a condição

Que desde o berço é razão

Desta minha nostalgia

Eu nasci na Mouraria

Na rua do Capelão

(Conde de Sobral, "Eu nasci na Mouraria")
} 
La rua do Capelão mencionada en los versos precedentes es la calle del barrio de Mouraria donde vivió la célebre fadista Maria Severa Onofriana, alusión que conecta al sujeto de este fado con la historia y el mito del género. $\mathrm{Al}$ igual que en el tango, hay cierta ambigüedad en la asimilación del destino impuesto por el espacio, en la medida en que aquel, aunque inevitable, es simultáneamente fuente de deseo y de tormento.

Hay cientos de tangos y fados escritos durante las décadas que tomamos en consideración en el presente trabajo, en los cuales los espacios superan la condición de meras escenografías y asumen un papel más o menos relevante. Por lo tanto, muchísimo más podría decirse y compararse sobre el tratamiento espacial en estas dos poéticas. Con las incipientes y primeras exploraciones aquí expuestas hemos postulado que las poéticas del tango y del fado están atravesadas por la experiencia de un espacio concreto, Buenos Aires y Lisboa respectivamente, de manera que se constituyen como géneros poético-musicales fuertemente localizados.

\section{CONCLUSIÓN}

Como es sabido, los movimientos críticos que buscan analizar e interpretar las significaciones de las distintas manifestaciones artísticas, ya sean literarias, pictóricas, musicales o de otra índole, no siempre provienen de miradas exteriores, como las de la academia. Muchas veces, en un giro metarreferencial, son esos mismos acontecimientos los que se miran a sí mismos y proponen repensar su historia, reinterpretarse, criticarse, renovarse o vincularse con otras artes. Por esa razón, hemos reparado en ciertas propuestas artístico-musicales surgidas en el marco de la música popular contemporánea argentina, cuyo propósito ha sido unir en mismo repertorio el tango y el fado. La agrupación conformada por Karina Beorlegui y los Primos Gabino ha sido pionera y emblemática de esta experimentación, en la que una misma voz y unos mismos instrumentos se ponen al servicio de dos géneros distintos. Esta confluencia en un mismo repertorio promueve la posibilidad de un diálogo entre dos géneros que orillan el atlántico en ubicaciones opuestas, 
pero en ciudades que manifiestan rasgos convergentes. Artistas y críticos han coincidido en señalar un factor geográfico común, la urbe portuaria, como la base sobre la cual se asentaron las poéticas del tango y del fado. Dicho espacio sería, por consiguiente, el fundamento de sus afinidades. Partimos de la concepción del puerto como estructura espacial y social condicionante (cfr. Sandrín y Biangardi, 2015: 8-9), que ha impactado esencialmente en la identidad urbana de Buenos Aires y de Lisboa. En consecuencia, en este artículo hemos pretendido aproximarnos a lo urbano-portuario como una categoría estética que nos permitiera entender el modo en que ambas ciudades fueron imaginadas por sus respectivas músicas.

En ese marco, nos hemos detenido en algunos rasgos coincidentes de la cartografía ficcional (Westphal, 2015: 53) de ambas ciudades trazadas por el tango y el fado: la relación del sujeto con el espacio, el anacronismo del imaginario urbano, su dimensión heterotópica y su carácter de espacios de resistencia cultural. Aunque dadas la vastedad y la heterogeneidad de ambas letrísticas dichos aspectos reclaman un mayor desarrollo, hemos podido advertir que tanto el tango como el fado configuran una poética del espacio caracterizada por una experiencia intimista de la ciudad, que cuestiona los límites entre el sujeto y el lugar, entre lo privado y lo público, lo íntimo y lo exterior, y en la que el espacio se percibe, por consiguiente, sustancialmente híbrido.

Quedan pendientes muchos otros aspectos para desentrañar de qué manera las letrísticas del tango y el fado han reconstruido sus referentes geográficos y le han otorgado nuevas significaciones. Entre ellos, por ejemplo, de qué manera dichas poéticas configuran las relaciones interpersonales en estos espacios, muchas veces signadas por el desencuentro o la imposibilidad de comunión; la emergencia de emociones vinculadas con la vivencia de la urbe portuaria o la posibilidad de entender estas ciudades imaginadas como espacios de amalgama e hibridación. 


\section{REFERENCIAS}

Bachelard, Gastón. La poética del espacio. Trad. Ernestina De Champourcin. Buenos Aires: Fondo de Cultura Económica, 2000.

Beorlegui, Karina. "Mucha mina", 15/7/2005. En https://www.pagina12.com. ar/diario/ suplementos/las 12/13-2077-2005-07-15.html . "El blues, el tango y el fado son lamentos poéticos y viscerales", 12/4/2013. En https://www.clarin.com/musica/karina_beorlegui_0_ ByD-aEFsw71.html . "Bohemia y poética en común", 2/6/2018. En https://www.pagina12. com.ar/118751-bohemia-y-poetica-en-comun

Campra, Rosalba. Como con bronca y junando. La retórica del tango. Buenos Aires: Edicial, 1996.

Castelo-Branco, Salwa El-Shawan. Voces de Portugal. Madrid: Akal, 2000.

Chandía Araya, Marco. "Manifestaciones tempranas en el imaginario de Valparaíso. En el contexto de una cultura porteña del Pacífico Sur”, Hybris 7 (2016): 61-93.

Elliott, Richard. Fado and the Place of Longing: Loss, Memory and the City. New York: Routledge, 2016.

Frith, Simon. Ritos de la interpretación: Sobre el valor de la música popular. Buenos Aires: Paidós, 2014.

Foucault, Michel. “Topologías”, Fractal 48/12/13 (2008): 39-62. En https:// www.mxfractal.org/RevistaFractal48MichelFoucault.html

García Brunelli, Omar. Discografia básica del tango: Su historia a través de las grabaciones (1905-2010). Buenos Aires: Gourmet Musical, 2010.

Gouveia, Daniel. Ao fado tudo se canta? Linda-a-Velha: DG Edições, 2013.

Gouveia, Daniel y Francisco Mendes. Poetas populares do fado tradicional. Lisboa: INCM, 2014.

Landaeta Mardones, Patricio, Braulio Rojas Castro y Alexis Candia-Cáceres. “Geofilosofía de la ciudad puerto", Hybris 7 (2016): 7-10.

Loraux, Nicole. La ciudad dividida: El olvido en la memoria de Atenas. Trad. Sara Vassallo. Madrid: Katz, 2008. 
Mayoral, José Antonio. Figuras retóricas. Madrid: Síntesis, 1994.

Mongin, Oliver. La condición urbana: La ciudad a la hora de la mundialización. Trad. Alcira Bixio. Buenos Aires: Paidós, 2006.

Pavão dos Santos, Vítor. O fado da tua voz: Amália e os poetas. Lisboa: Bertrand Editora, 2014.

Romano, Eduardo. Las letras del tango: Antología Cronológica 1900-1980. Rosario: Fundación Ross, 1993.

Russo, Fabián. El tango cantado: Una lectura acerca del canto en la Escuela Gardeliana. Buenos Aires: Corregidor, 2011.

Sandrín, María Emilia y Biangardi, Nicolás (comps.). Los espacios portuarios: Un lugar de encuentro entre disciplinas. La Plata: Universidad Nacional de La Plata. Facultad de Humanidades y Ciencias de la Educación, 2015.

Schvartzman, Julio. "El tango en el tango". Las poéticas del tango canción: Rupturas y Continuidades. Oscar Conde (ed.). Buenos Aires/Remedios de Escalada: Biblos/Ediciones de la UNLA, 2014. 163-181.

Sucena, Eduardo. Lisboa, o Fado e os Fadistas. Lisboa: Nova Vega, 2008.

Taylor, Diana. "Hacia una definición de «performance»", Picadero 15 (2005): 3-5. . Performance. Buenos Aires: Asunto Impreso, 2012.

Tuan, Yi-Fu. Topofilia: Un estudio de las percepciones, actitudes y valores sobre el entorno. Trad. Flor Durán de Zapata. Barcelona: Melusina, 2007.

Ulla, Noemí. Tango, rebelión y nostalgia. Buenos Aires: Centro Editor de América Latina, 1982.

Varela, Gustavo. Tango y política: sexo, moral burguesa y revolución en Argentina. Buenos Aires: Ariel, 2016.

Vera Sepúlveda, Miguel Ángel. "Género portuário: Marco teórico de uma investigação antropológico-musical". Ao fado tudo se canta? Daniel Gouveia. Lisboa: DG Edições, 1999. 230-233.

Vieira Nery, Rui. Para uma história do Fado. Lisboa: Público, 2004. 
Westphal, Bertrand. "Aportes para un enfoque geocrítico de los textos". Espacios, imágenes y vectores: Desafios actuales de las literaturas comparadas. Mariano García, María José Punte y María Lucía Puppo (comps.). Buenos Aires: Miño y Dávila, 2015. 